\title{
Séculos de história indígena no coração da América do Sul: os chiquitano no (atual) oriente boliviano
}

Giovani José da Silva*

Resumo: Outrora conhecidos também como Trabacicosis ou Tapuymirí, Chiquito ou Chiquitano hoje em dia é, genericamente, a definição de um cadinho de grupos indígenas, os mais variados, reunidos graças à ação missionária jesuítica (1691-1767) nas atuais "terras baixas" bolivianas. Esta ação pode ser resumida em dois aspectos principais: a aglomeração de indígenas em reduções ou missões e a imposição de uma única língua, o Chiquitano, como língua geral. Sobre a história do grupo, é possível se estabelecer uma divisão em fases: de 1542 a 1620 (conquista e subjugo dos indígenas), 1620 a 1692 (perambulação de vários grupos pela Chiquitania e eventual caça de índios, pelos espanhóis e portugueses, para escravização), 1692 a 1767 (cristianização dos indígenas), 1767 aos nossos dias (eventos que assinalam intenso contato entre os Chiquitano e não índios, após o período reducional). Se por um lado as missões jesuíticas constituíram-se em um evento incisivo na história dos Chiquitano, por outro propugnaram a destruição de tradicionais estruturas políticas, sociais, econômicas, culturais e religiosas, assim como a mistura entre grupos diversos, alguns até mesmo inimigos entre si. O passado e o presente dos Chiquitano estão intimamente relacionados com o projeto missionário jesuítico, desenvolvido entre o final do século XVII e o início da primeira metade do século XVIII. Tentativas de convivência, imposição de pautas culturais, ressignificação de práticas e representações, diálogos interculturais e resistências armadas foram ingredientes presentes nessa história. O objetivo do

* Professor de História da América na Universidade Federal de Mato Grosso do Sul - UFMS. Pós-Doutorado em Antropologia na Universidade de Brasília - UnB. E-mail: giovanijsilva@hotmail.com. Endereço: Caixa Postal 121. CEP: 79750-000 - Nova Andradina - MS. 
artigo é, pois, apresentar uma síntese da trajetória etno-histórica dos indígenas Chiquitano, entre os séculos XVI e XX.

Palavras-chave: História Indígena. Chiquitano. América do Sul. Oriente boliviano. Missões Jesuíticas.

\section{Introdução}

O objetivo do artigo é apresentar uma síntese da trajetória etno-histórica dos indígenas Chiquitano, que viveram em terras da América espanhola ao longo dos séculos XVI a XVIII e início do XIX, bem como na Bolívia, nos séculos XIX e XX. Para tanto, foram realizadas pesquisas em arquivos e leituras em bibliografia especializada, no Brasil e naquele país. Os resultados foram transformados em tese de doutorado em História, defendida em 2009 na UFG (Universidade Federal de Goiás), pelo autor (JOSÉ DA SILVA, 2009). O texto a seguir é parte dos resultados do referido trabalho.

Como república independente, a Bolívia formou-se, no plano político, a partir de 1825, sobre a base territorial da antiga Real Audiência de Charcas. Tornando-se um país emancipado politicamente na primeira metade do século XIX, “[...] constituiu-se assim na mais indígena das novas repúblicas da [antiga] América espanhola [...] (KLEIN, 1991, p. 73)". Até então, ao longo do período colonial, as atuais terras bolivianas fizeram parte, primeiro, do Vice-Reino do Peru (1543) e, posteriormente, quando o mesmo foi dividido, do Vice-Reino do Prata (1776). A conquista espanhola nessa porção da América seguiu o modelo precedente da conquista do México e de parte da América Central, em que uma avançada tecnologia militar possibilitou que centenas de espanhóis sobrepujassem, em pouco tempo, grupos indígenas formados por milhares de homens e mulheres.

Diversos grupos povoaram em tempos pretéritos as terras bolivianas, formando distintos e importantes conjuntos culturais. Antes da chegada dos espanhóis, entre o século XII e as primeiras décadas do século XVI, floresceram, nos planaltos andinos do Sul, uma sociedade ancorada em um denso sistema de aldeias agrícolas. Algo em torno de três milhões de indígenas estava sob o controle do Inca, envolvendo uma multiplicidade de distintas sociedades, falantes 
de numerosas línguas, que se agrupavam numa vasta estrutura de trocas, não mercantil. Já na região das planícies, desenvolveu-se um sistema de povoamento paralelo ao andino, que formava uma espécie de "fronteira" integrada por uma combinação de grupos caçadores, coletores e agricultores (WACHTEL, 2004, p. 232-233).

Esta verdadeira "fronteira humana" impediu a expansão dos grupos andinos nesses domínios territoriais, além de conter os avanços da colonização ibérica na região. Já em tempos précoloniais, a atual região da Chiquitania esteve povoada por inúmeras etnias pertencentes a diversos grupos linguísticos. Apesar dos poucos dados disponíveis, é possível afirmar que os Chiquitano não conformaram uma sociedade fortemente estratificada, com sistema de cacicatos e que tal modelo teria sido introduzido pelos jesuítas (RIESTER, 1976; KREKELER, 1995).

Em relação à localização geográfica, uma das primeiras delimitações da área então conhecida como "Nación de los Chiquitos" aparece em um memorial de 1703, escrito por Francisco Burgés, então Procurador Geral da Província Jesuítica do Paraguai:

La Nación de los Chiquitos confina por el Occidente con la Ciudad de San Lorenço y Provincia de Santa Cruz de la Sierra. Su distrito corre azia el Oriente hasta el Río Paraguay por espacio de ciento y cuarenta leguas; por la parte del Norte se termina en la Sierra de los Tapacuras, que divide esta Missión de la de los Moxos, y corre la Serranía desde el Poniente al Oriente hasta el dicho Río Paraguay. Y por la parte del Sur confina con Santa Cruz la Vieja y su Serranía, que assimismo corre hasta el mismo Río. La distancia que ay de Norte à Sur será de cien léguas (apud TOMICHÁ CHARUPÁ, 2008, p. 237-238).

Tais limites, confirmados em outra fonte da época (FERNÁNDEZ, 1895; 1896), correspondem, grosso modo, à região onde se estabeleceu a experiência reducional promovida pelos jesuítas no atual Oriente boliviano. O uso do vocábulo "Nación", por Burgés, inclusive, permite entrever certa hegemonia geográfica e sociocultural do grupo étnico majoritário conhecido como Chiquito ou 
Séculos de história indígena no coração da América do Sul...

Chiquitano. O mesmo jesuíta assinala, em outros trechos de seu memorial, os diversos grupos que existiam, então, na região, pertencentes a inúmeras famílias linguísticas.

Outrora conhecidos também como Trabacicosis ou Tapuymirí, Chiquito ou Chiquitano atualmente é, genericamente, a definição de um cadinho de grupos indígenas, os mais variados, reunidos graças à ação missionária jesuítica (1691-1767) nas “terras baixas” bolivianas. Esta ação pode ser resumida em dois aspectos principais: a aglomeração de indígenas em reduções (com a consequente e progressiva sedentarização dos grupos) e a imposição de uma única língua, o Chiquitano, como língua geral (chamada, hoje em dia, de Chiquito pelos linguistas e de Besüro ou Besoro pelos próprios indígenas).

A propósito da razão do nome Chiquitos ou Chiquitano, escreveu o jesuíta Diego Martínez ao provincial Juan de Atienza, em 19 de novembro de 1592:

[...] tienen sus casas muy pequeñas y bajas las puertas, que se entra a gatas, y por eso les pusieron por nombre chiquitos, porque ellos son gente muy dispuesta y fornida, y casi toda gente moza, hay muy pocos viejos, porque dice murieron de una pestilencia, duermen en unas camillas como zarzos, altas del suelo, angostas y cortas, que es menester encoger las piernas, hechas de unos palos rollizos partidos por medio y lo rollizo arriba, que me parece que los monjes del hierro dijeran ser la más estrecha penitencia, si la hicieran por amor de Dios (apud TOMICHÁ CHARUPÁ, 2005, p. 14).

Alfred Métraux (1942), entretanto, aponta para outra possibilidade para a origem do nome Chiquitano ou Chiquito: tais expressões poderiam ser derivadas da língua Guarani, tapuy miri, ou "inimigos pequenos", traduzido pelos espanhóis por chiquitos. De qualquer forma, seria um erro pensar que as portas das casas dos indígenas fossem rebaixadas apenas por causa da pequena estatura dos mesmos. É provável que tal recurso fosse uma forma, bastante eficaz, de evitar a entrada de mosquitos e outros insetos nas moradias.

A respeito das religiosidades tradicionais dos grupos indígenas da Chiquitania, na época colonial, dispõe-se de dados esparsos, 
coletados nos manuscritos deixados por alguns dos jesuítas que entraram em estreito contato com tais grupos. Tanto Juan Patrício Fernández como Julián Knogler observaram, por exemplo, que os nativos não adoravam ídolos. Fernández (1895; 1896) dá alguns detalhes, afirmando que os índios consideravam a lua como uma espécie de diosa ou madre, sem, contudo, adorá-la. Os indígenas criam na sobrevivência das almas após a morte, evitando pronunciar os nomes dos mortos, e interpretavam trovões e raios como pelejas entre espíritos malignos. Prestavam grande atenção no voo e canto dos pássaros, no comportamento dos animais e no crescimento das plantas, verificando "avisos" nestes fenômenos.

Os xamãs tinham grande importância, pois eram vistos como mediadores entre os homens e as forças da natureza. O missionário Lucas Caballero, além dos já citados Fernández e Knogler, os menciona também em seus escritos (KREKELER, 1995). Para Knogler, os Chiquitano tinham em alta honra o que ele considerava como "charlatães" (RIESTER, 1970). Nesse aspecto, os xamãs tinham tanto poder quanto os caciques. Com exceção desses, a maioria dos indígenas andava nua, porém com os genitais cobertos. São escassas as descrições dos bens materiais de que dispunham os Chiquitano. Digno de menção é o uso de redes, existentes, ao que parece, em todas as partes, costume que se conserva até os dias de hoje. Knogler afirma que as redes eram usadas como camas e que poderiam ser levadas facilmente de um lugar para outro, protegendo os indígenas dos ataques de répteis e insetos (RIESTER, 1970).

Métraux (1942, p. 114) ainda reporta-se à complexidade de se determinar com exatidão quem foram os Chiquitano e onde os mesmos se localizavam. Sobre a história do grupo, Birgit Krekeler (1995) destaca, grosso modo, uma divisão em fases: de 1542 a 1620 (conquista e subjugo dos indígenas), 1620 a 1692 (perambulação de vários grupos pela Chiquitania e eventual caça de índios, pelos espanhóis e portugueses, para escravização), 1692 a 1767 (cristianização dos indígenas), 1767 aos nossos dias (eventos que assinalam intenso contato entre os Chiquitano e não índios). De acordo com Krekeler, se por um lado as missões jesuíticas constituíram-se em um evento incisivo na história dos Chiquitano, por outro propugnaram a destruição de tradicionais estruturas políticas, sociais, econômicas, 
culturais e religiosas, assim como a mistura entre grupos diversos, alguns até mesmo inimigos entre si (KREKELER, 1995, p. 217).

O passado e o presente dos Chiquitano estão intimamente relacionados com o projeto missionário dos jesuítas, desenvolvido entre o final do século XVII e o início da primeira metade do século XVIII. Contudo, em contrapartida à sobrevivência física representada pelas missões e para além dos esforços dos religiosos em adequar seus métodos de evangelização àquela realidade, a vida nas missões implicou, para os Chiquitano e para os outros grupos reduzidos, uma série de mudanças em suas pautas culturais, desde os aspectos religiosos e econômicos até os sociopolíticos. Impuseram-se crenças e rituais católicos, introduziu-se a criação de gado e houve o incremento da atividade agrícola, dentre outras profundas mudanças operadas ao longo tempo. Implantou-se, ainda, paulatinamente, uma estrutura social organizada verticalmente e composta por rígidas hierarquias até então desconhecidas pelos indígenas.

A inserção dos missionários em toda a América mesclou conhecimentos tradicionais dos nativos com os valores cristãos e europeus trazidos pelos inacianos. Em outras palavras, teria ocorrido um encontro/confronto característico de áreas de fronteiras, no caso das Coroas espanhola e portuguesa nas Américas, entre os religiosos e as etnias da Chiquitania. Tentativas de convivência, imposição de pautas culturais, ressignificação de práticas e representações, diálogos interculturais e resistências armadas foram ingredientes presentes nessa história. Uma experiência, sem dúvida, radicalmente transformadora para ambos: missionários e indígenas.

\section{A época das missões (1691 a 1767)}

No mesmo ano em que os Chiquitano solicitaram ajuda do governador Agustín de Arze contra os bandeirantes paulistas, em 1690, chegou a Santa Cruz o jesuíta José de Arce, que pretendia fundar missões entre os Chiriguano (KREKELER, 1995, p. 51). O governador o desaconselhou, entretanto, afirmando terem aqueles índios fama de "indomáveis" e "cruéis" e recomendou fundar missões entre os Chiquitano, posto ter interesse na reconquista da Chiquitania. 
Assim, Arce fundou a redução de San Francisco Javier, em 1691. Especialistas, como Tomichá Charupá (SILVA, 2008), chamam a esse período de o início da "formação da cultura Chiquitano".

Não apenas entre os Chiquitano houve experiências reducionais: as mesmas já haviam sido iniciadas entre os Moxo (Loreto, San Ignacio, Trinidad e San Xavier) e estendidas aos Chiriguano (San Juan Bautista de Porongo e Santa Rosa del Sara), Guarayo (San Pablo y Ascensión) e Yuracaré (Potrero de Santiago). As reduções de Moxos e Chiquitos foram administradas por jesuítas, enquanto as de Guarayos, por franciscanos. As missões entre os Chiriguano, empreendidas por franciscanos, jesuítas e dominicanos, não tiveram grande êxito, do ponto de vista dos religiosos. De modo geral, a vida nas reduções comportava, dentre outros aspectos, um rápido processo de sedentarização de grupos nômades e seminômades, o surgimento ou incremento de atividades agropecuárias e artesanais, a exportação de excedentes produtivos e a progressiva assimilação de um ritmo de vida inspirado em valores europeus e cristãos (TOMICHÁ CHARUPÁ, 2005).

Já em 1692 houve uma sangrenta batalha entre os Chiquitano da recém-fundada Missão de San Francisco Javier, sob o comando de Arce e mais 130 soldados enviados de Santa Cruz (comandados pelo governador José Robledo de Torres), contra cerca de 150 membros de uma bandeira, que terminaram derrotados por completo, com poucos sobreviventes e alguns fugitivos (FERNÁNDEZ, 1895, p. 98-101). ${ }^{1}$ Até o final do século XVII seguiram-se as fundações de mais três reduções: San Rafael, fundada em 1696 pelos padres Juan Bautista Zea e Francisco Hervas; San Jose, erigida entre 1696 e 1698, pelos padres Felipe Suaréz e Dionisio de Ávila; finalmente, San Juan Bautista, iniciada pelos padres Juan Bautista Zea, Juan Patrício Fernández e Juan Bautista Jandra, em 1699, e somente concluída em 1716.

Acerca da fundação desta última missão, sabe-se que de San Jose foram formados dois batalhões de indígenas convertidos, a fim de reduzir os indígenas Puraxi. Contudo, enquanto o primeiro grupo regressou com aproximadamente cinquenta famílias, o segundo foi completamente exterminado pelos indígenas resistentes, o que provocou a formação de uma nova expedição, composta, desta vez, 
por cem índios fortemente armados. Os Puraxi foram massacrados e os poucos sobreviventes obrigados a ingressarem na nova reducción, sob as ordens dos missionários.

Em 1706, editos régios prescreveram para as reduções, na América do Sul, a isenção de tributo dos indígenas por vinte anos; a proibição de repartir indígenas aos encomenderos; a organização dos indígenas em povoados; a obediência estrita das Leyes de Índias, no sentido que os Chiquitano não deveriam ser recrutados para os trabalhos nas minas de Potosí (FINOT, 1978, p. 340). La Concepción foi fundada a partir de 1709 por Lucas Caballero e terminada pelo Padre Juan Benvanente, em 1722. O padre Caballero foi assassinado em 1711 pelos Puyzoca e contra estes indígenas os jesuítas organizaram expedições, apoiando uma companhia de soldados destacados de Santa Cruz, chamados a vingar a morte do missionário (FERNÁNDEZ, 1895, p. 82).

San Miguel foi erigida por Felipe Suárez, em 1721 e três anos depois, em 1724, o padre Agustín Castanares fundou a Missão de San Ignacio de Zamuco, em territórios de indígenas Zamuco, Аyoréo, Ugron, Tapio e Satieno, mas esta missão foi abandonada em 1745, em razão de lutas internas entre duas parcialidades Zamuco (TONELLI JUSTINIANO, 2004, p. 67). Entre 1725 e 1747, não foram fundadas outras missões na Chiquitania, conformando-se um período de consolidação daquelas que já haviam sido erigidas. Além disso, esse período é marcado pela expedição de diversos documentos pela Coroa, na tentativa de regulamentar a presença jesuítica nas Américas, bem como dos trabalhos desenvolvidos pelos religiosos junto às populações indígenas reduzidas.

A uma carta endereçada ao rei Felipe V, pelo procurador geral da província do Paraguai, José Rico, em 1742, seguiu-se um edito régio, a Real Cédula, de 17 de dezembro de 1743, em que a Coroa espanhola confirmava o poderio dos jesuítas sobre toda a província de Chiquitos, "[...] enque se comprenden todas las naciones o parcialidades de indios que hay entre los rios Pilcomayo y Paraguay, desde las vecindades de Santa Cruz de la Sierra" (apud FINOT, 1978, p. 343). O mesmo documento determinava que se fizesse a contagem dos índios das missões de Chiquitos, o que ocorreu em 1745, por meio de um censo elaborado por Francisco de Palácios. 
O censo faz referências a 51 grupos reduzidos, perfazendo um total de 14.701 habitantes nas missões (MOLINA MOSTAJO, 1936, p. 93). Tais números aproximam-se dos dados expostos pelo jesuíta Martín Schmid, que, em uma carta datada de 1744, enumerou 14.232 indígenas reduzidos (KREKELER, 1995, p. 54).

Após 1747 foram fundadas outras quatro missões em territórios dos Chiquitano: San Ignacio de Chiquitos, Santiago, Santa Ana e Santo Corazón de Jesús. San Ignacio foi fundada em 1748 pelo padre Miguel Areijer. Santiago, erigida em 1754 pelos padres Gaspar Troncoso e Gaspar Campos, foi transferida de local em 1764 pelos padres Patricio Patsi e José Pelayas. Santa Ana foi fundada em 1755 pelo padre Knogler. Por fim, em 1760, foi fundada a última redução na Chiquitania, a de Santo Corazón de Jesús, pelos padres Antonio Gaspar e José Chueca.

Além de questões estratégicas, as principais causas que levaram os jesuítas a mudar a localização de algumas das reduções foram, dentre outras, o fato de estarem localizadas em paragens que resultaram insalubres; a esterilidade dos solos, o que colocava em risco a alimentação dos habitantes reduzidos; lugares excessivamente expostos ao ataque de inimigos; escassez de água e uma topografia muito plana, que não permitia a construção de pequenos diques e açudes.

A presença jesuítica nas missões de Chiquitos pode ser mais bem compreendida ao se verificar três etapas claramente distintas na ocupação da Chiquitania. A primeira etapa estendeu-se por mais de 30 anos (1691-1724) e se caracterizou pela entrada dos padres da Companhia de Jesus em territórios Chiquitano, a fim de explorá-los, dirigindo seus maiores esforços à reabertura do antigo caminho dos primeiros conquistadores, de Assunção à Santa Cruz de la Sierra, la vieja. Neste período, a evolução demográfica das missões foi muito lenta, posto que as reduções sempre estiveram ameaçadas por graves enfermidades de caráter epidêmico, fazendo com que muitos indígenas adoecessem, enquanto os sobreviventes fugiam, buscando proteção nas matas.

A segunda etapa da história das missões abarca aproximadamente 22 anos (1725-1747), período em que os jesuítas dedicaramse a continuar explorando os territórios Chiquitano, consolidando seus domínios; a converter o maior número de indígenas à religião 
católica, tarefa a qual Knogler, fundador da Missão de Santa Ana, deu o nome de "caza espiritual de salvajes" (RIESTER, 1970); lograr estabilizar as missões fundadas até então, conseguindo, assim, maiores avanços espirituais e materiais. Como visto, nessa segunda etapa não foi fundada nenhuma outra redução na Chiquitania e a intenção dos jesuítas em obter uma rota das missões de Chiquitos até o Paraguai fracassou, conseguindo-se, entretanto, abrir um caminho de passagem que ligava as reducciones até a região de Tucumán, próximo à Cordilheira dos Andes, partindo-se da Missão de San Jose e cruzando-se parte do Chaco.

A terceira e última etapa da história das missões jesuíticas de Chiquitos vai de 1748 a 1767, durando, portanto, pouco menos de vinte anos. Nesta derradeira etapa, foram criadas novas reduções e o número de índios reduzidos cresceu consideravelmente. Devese ressaltar que nesta etapa a caza espiritual dos chamados "infiéis" permitiu não apenas a formação das últimas cinco novas missões, mas também que as mais antigas seguissem crescendo em tamanho e número de habitantes.

As missões, de certa forma, continuavam a desempenhar o papel de "sentinelas" das fronteiras entre as duas Coroas:

El emplazamiento de tres de estos pueblos [Santiago, Santa Ana e Santo Corazón] perseguía la ocupación de la vasta zona que se extendía al este de la misión de San Juan Bautista hasta el río Paraguay. Mientras que Santa Ana, por su ubicación, vigilaba y cuidaba el único camino que por entonces vinculaba Chiquitos con el Brasil, específicamente con Vila Bela [da Santísima Trindade] y Cuiaba. Esta aldea en la época y más adelante, se constituyó en un centinela, celando la frontera nordeste del territorio (TONELLI JUSTINIANO, 2004, p. 76).

Para esse período, as fontes são essencialmente aquelas deixadas pelos jesuítas Fernández, Knogler e Schmid, que conviveram nas missões com muitos grupos diferentes e deixaram, sobre os Chiquitano, interessantes observações de cunho etno-histórico. 
Evidentemente que tais relatos devem ser apreciados tendo em vista o principal objetivo desses padres, que era a evangelização.

Os métodos para atrair os indígenas consistiam na persuasão, oferecendo presentes em troca da proteção dos espanhóis, sobretudo instrumentos de ferro muito desejados por todas as etnias das "terras baixas", e também na captura pela força. As escassas fontes sobre as missões de Chiquitos revelam fortes indícios a respeito das estratégias de se oferecer pequenos regalos, que eram distribuídos entre os indígenas, atraindo-os para a fé católica e tornando-os dependentes dos não índios.

O melhor exemplo dessa estratégia está nas viagens do padre Lucas Caballero, que durante anos perambulou pelos territórios dos Tapacura, Paunaca, Unape, Manaica, Sibaka e Quiriquica, repartindo ferramentas entre os mesmos. Depois de algum tempo, com a extrema dependência criada pelo jesuíta, os indígenas aceitaram voluntariamente a fundação da redução de La Concepción (FERNÁNDEZ, 1895, p. 234-259; 1896, p. 07-69). Contudo, ainda que esses métodos tivessem um relativo êxito, numerosos grupos retiraram-se para áreas menos acessíveis, a fim de fugir tanto dos espanhóis, de forma geral, quanto dos jesuítas. As reduções estavam divididas em parcialidades em que cada grupo étnico vivia separado dos demais e era encabeçado por um cacique. Para contornar o problema linguístico, o Chiquito - o idioma mais difundido na região - foi declarado "língua geral" ou "língua franca".

As missões diminuíram a gama de produtos elaborados a partir de plantas silvestres, substituindo-lhes por produtos manufaturados, para os quais se formaram especialistas indígenas em múltiplos ramos artesanais. No sistema das reduções, os indígenas eram responsáveis pela mão de obra, tendo que produzir para sua subsistência e gerar excedentes de produtos agrícolas ou em forma de cera, telas e outros artigos, que eram trocados por bens que faltavam nas reduções ou que se vendiam a outras regiões. Contudo, os missionários nunca lograram o abastecimento completo de proteína animal, razão pela qual os indígenas regressavam às matas, por épocas curtas, para caçar e pescar, o que lhes deu a oportunidade de reproduzir temporariamente seu estilo de vida tradicional e de conservar e aplicar os conhecimentos sobre seu habitat. 
Séculos de história indígena no coração da América do Sul...

Nas reduções, os jesuítas impuseram uma estrutura política hierarquizada: o cabildo, conformado por vários cargos políticos desempenhados por indígenas de diferentes parcialidades. $\mathrm{O}$ missionário que encabeçava cada redução tinha poder absoluto e se servia das autoridades indígenas cuja posição fortalecia, concedendolhes diversos privilégios para fazer funcionar as missões nos planos organizativo, econômico e religioso. Os caciques tinham que dirigir os assuntos de sua respectiva parcialidade, manter a ordem nas missões e supervisionar o cumprimento dos trabalhos. Apesar do grande número de indígenas instalados em cargos, o poder efetivo nas missões continuava nas mãos dos missionários e isso explica porque apenas dois deles (um para a administração dos bens e outro para o trabalho espiritual), em cada redução, conseguiram controlar um grande número de indígenas.

Todas as missões estavam organizadas seguindo os mesmos princípios. As reduções da Chiquitania eram economicamente autônomas, possuindo parte delas um grande número de gado bovino e equino. Somente a Missão de San Jose teve, em certa época, aproximadamente 11.000 cabeças de gado vacum (FINOT, 1978, p. 351). Por outro lado, os homens tinham que cultivar a terra, além de aprender outros diferentes ofícios. Os Chiquitano trabalhavam a terra comunal de dois a três dias por semana, guardando as colheitas em depósitos. Estas colheitas estavam destinadas, sob a supervisão estrita dos jesuítas, a pagar o tributo real, além da manutenção dos padres e da Igreja; a manutenção dos órfãos, viúvas, idosos e enfermos; o que restava era servido como alimentação às famílias. As terras daqueles que se ocupavam de tecelagem, metalurgia e carpintaria ou, ainda, que serviam nas milícias, eram trabalhadas pelos demais.

Do projeto de reunião das múltiplas etnias e de evangelização, que representava o sistema reducional, surgiu o povo Chiquitano, tal como se conhece hoje em dia. Assim, as chamadas reducciones constituíram o sistema de maior impacto no modelo de povoamento indígena, essencialmente disperso. Mediante essa instituição, a Coroa espanhola tratou de concentrar a população nativa, fixando-a de modo que formassem os denominados "povoados de índios". Em 1767 havia 23.788 indígenas batizados nas dez reduções de Chiquitos. Contudo, Knogler (RIESTER, 1970) deixou registrado que se 
levando em conta os indígenas batizados e não batizados havia um contingente de cerca de 37.000 índios. Ainda que as missões tivessem uma tarefa eminentemente religiosa, estas dependiam dos interesses e das pretensões da Coroa espanhola. Assim, as autoridades estatais espanholas utilizaram-se dos trabalhos missionários para subjugar aos Chiquitano e outros grupos indígenas, ocupar efetivamente a região e proteger as fronteiras.

De acordo com Eulália M. L. Lobo (1960), após a expulsão dos jesuítas. verifica-se, por meio da documentação, um intenso comércio clandestino de gado e gêneros alimentícios entre Chiquitos e Mato Grosso, havendo condições favoráveis para tal intercâmbio. Apesar das inúmeras restrições de atividades comerciais entre as duas regiões por parte do governo espanhol, em tensas relações diplomáticas com a Coroa portuguesa em meados do século XVIII, o contrabando ("descaminho") e os roubos eram bastante comuns. Os portugueses viam com bons olhos a manutenção do comércio das antigas missões de Moxos e Chiquitos com as fronteiras lusobrasileiras. As instruções régias para o governador e capitão general da então Capitania de Mato Grosso, Luís de Albuquerque de Melo Pereira e Cáceres, de 13 de agosto de 1771, deixam patente tal desejo da Coroa lusa. Por conta dessa situação. foi fundado, em 1778, o porto de Albuquerque, que daria origem, algum tempo depois, à cidade de Corumbá, na margem direita do Paraguai.

\section{Do fim das missões ao início do primeiro auge da exploração da borracha (1767 a 1880)}

No ano de 1767, sob o domínio de Carlos III (1759-1788), a Espanha pôs um ponto final na obra reducional, mediante a expulsão dos jesuítas da América do Sul. No total, foram expulsos 24 jesuítas com a chamada Extradición. Os interesses do Estado e da Igreja nesse período eram cada vez mais discrepantes. Reportavase aos jesuítas, dentre outras coisas, a usurpação da soberania da Coroa nas reduções e a incitação a rebeliões indígenas. Ainda assim, existiam queixas contra o não pagamento de dízimos e as disputas de outras ordens em relação aos inacianos. Depois da expulsão, as 
missões foram transferidas, sobretudo, a sacerdotes franciscanos e seculares e, posteriormente, a funcionários públicos. Muitos dos Chiquitano não aceitaram as novas imposições, acreditando, inclusive, no retorno dos jesuítas.

Foi, então, quando chegaram os primeiros habitantes de Santa Cruz de la Sierra à Chiquitania, onde fundaram estâncias, com o gado das reduções. Uma parte dos indígenas, sobretudo a que estava há pouco tempo nas missões, retirou-se para as matas e tentou retomar seu antigo modo de vida; outros permaneceram e trataram de manter a ordem e os costumes que haviam adotado nas reduções. Os conflitos entre os novos sacerdotes e os funcionários, sua incapacidade de administrar as reduções, a intensiva exploração dos indígenas por autoridades religiosas e leigas, o recrutamento dos habitantes das missões pelos criadores de gado como mão de obra nas estâncias e a resistência daqueles contra a nova ordem resultou na paulatina decadência do sistema reducional que finalmente foi abolido, na década de 1850 .

Após a independência, em 1825, o governo da nova República da Bolívia repartiu as terras na Chiquitania a não índios e mestizos de Santa Cruz. O requerimento de mão de obra foi coberto mediante o empadronamiento forzoso dos Chiquitano, imposto pelo governo. Este sistema significou praticamente a escravidão dos indígenas, que passaram a ser propriedade de seus patrões, que podiam vendê-los junto com as terras. O sistema reducional foi abolido pelo governo, durante o século XIX, certamente tendo em vista as ideias liberais muito em voga naquele momento histórico. Inspirado em tais ideias, o viajante José Esteban Grondona (1942) escreveu a Descripción Sinóptica de la Provincia de Chiquitos, com importantes informações sobre a região e uma crítica contundente ao sistema reducional, até então vigente. Grondona atribuía o atraso da província a três causas principais: a contribuição pessoal a que estavam submetidos muitos indígenas, chamada de tributos ou impuestos; a escravidão com que se subjugavam outros tantos índios; a ausência do direito ao livre comércio, uma vez que os indígenas estavam submetidos à tutela de governadores e administradores.

Ainda para a primeira metade do século XIX, as informações a respeito dos Chiquitano registradas por Alcide Dessalines D’Orbigny 
são igualmente valiosas. D’Orbigny (1845) visitou as antigas missões de Chiquitos e Moxos, apreciando as habilidades dos indígenas para a execução de música erudita (desenvolvidas durante o período jesuítico e mantidas até os dias de hoje pelos atuais Chiquitano, na Bolívia). Ele observou, por exemplo, que as mulheres Chiquitano fiavam algodão, como já faziam nas missões (KREKELER, 1995, p. 138). Nas visitas que realizou às outrora reduções jesuíticas, D’Orbigny constatou que as línguas locais de diversos grupos haviam desaparecido ou eram faladas por poucas pessoas. Havia, pois, uma predominância da língua Chiquitano, em detrimento de línguas Aruak e Chapacura, todavia ainda faladas até aquele momento.

Os dados demográficos dos Chiquitano para a primeira metade do século XIX são escassos. Nos censos de 1805 e 1825, contabilizaram-se, respectivamente, 21.951 e 17.286 indígenas vivendo nas antigas reduções, chamadas a partir daquele período de pueblos. Por ocasião das guerras pela independência da Bolívia (1809-1825), a população dos pueblos tornou-se leal à Coroa Espanhola e as tropas, compostas em sua maioria por indígenas Chiquitano, foram esmagadas, em 1815, na batalha de Santa Bárbara.

Um censo realizado em 1826, por ordem do prefeito de Santa Cruz de la Sierra, Jose Miguel de Velasco, contabilizou 17.315 indígenas, o que, de certa forma, confirma os dados do censo de 1825. Quatro anos mais tarde, em 1830, D’Orbigny registrou 15.316 indígenas vivendo na mesma região (TONELLI JUSTINIANO, 2004, p. 170). O decréscimo verificado em tão pouco tempo foi atribuído às epidemias de varíola que grassavam a Chiquitania, além da escassez generalizada de alimentos. D'Orbigny foi um dos primeiros viajantes a divulgar, por meio de seus escritos, as riquezas minerais da Chiquitania. Não apenas atestou a presença de ouro, mas também ferro, cobre, mica, prata, estanho e, até mesmo, de pedras preciosas.

A existência de ouro na região foi noticiada em 1844 e logo se espalhou por toda a Chiquitania, que foi invadida por não indígenas provindos de Santa Cruz, além de estrangeiros. Surgiu nessa época a povoação de Santa Rosa de la Mina, até então chamada de Quebrada Ancha. A "febre do ouro" tomou conta da região até o início da década de 1890, quando os rendimentos das escavações começaram a decrescer consideravelmente. Os indígenas não 
usufruíram economicamente dessa atividade e sequer vislumbraram a possibilidade de explorar os metais e pedras preciosas, uma vez que eram utilizados apenas na atividade de extração como mão de obra a serviço dos não indígenas.

Gabriel René Moreno, em 1880, referiu-se à "deterioração econômica e social" por ele observada na Chiquitania (TONELLI JUSTINIANO, 2004, p. 192-193). Tal “deterioração" referia-se à supressão do sistema reducional jesuítico, que, segundo o autor, ao invés de promover a melhoria das condições dos Chiquitano, ao longo do século XIX, pelo contrário, aprofundou a decadência econômica da região, lançando os indígenas em um sistema de trabalho opressor e, praticamente, escravo. Apesar de terem sido os jesuítas quem introduziram a cana-de-açúcar na Chiquitania, foi no século XIX que se começou a fabricar na região grandes quantidades de álcool, com o qual se subjugou, por meio do vício, os indígenas, convertendo-os em trabalhadores servis das chacras, establecimientos e estancias. Além disso, a extração da borracha no final do século XIX e nas duas primeiras décadas do século XX, na Bolívia e no Brasil, foi um fator de grave de diminuição da população entre os Chiquitano.

\section{Os chiquitano entre o final do século XIX e a primeira metade do século $\mathrm{XX}^{2}$}

Como resultado do primeiro auge da exploração da borracha, formaram-se inúmeras comunidades compostas por indígenas de distintas etnias. Apenas na Província de Velasco, datam desta época: San Javierito, Santa Rosa de Roca, Santa Teresa, San Francisco Guarrío, San Juancito, Santa Teresita de los Sujales, San Miguelito (na área de fronteira com o Brasil) e El Cerrito, dentre outras. Algumas comunidades começaram a ser organizadas na região entre 1920 e 1930, quando a exploração da borracha entrou em progressivo declínio: Sañonama, Espiritu, Carmencita, Recreo, San Antonio, Mercedes - Las Minas y Papayo. Na área de influência de San Jose, surgiram as comunidades de Quituquiña, Dolores e Pororó. Um 
grande número de comunidades também foi fundado logo depois da Guerra do Chaco, no final da década de 1930.

O censo de 1900 registrou uma população de 32.295 habitantes na Chiquitania, sendo 17.812 na zona urbana e 14.483 na zona rural. A Chiquitania, nessa época, já se encontrava dividida em duas províncias: Velasco (criada em 1880, com capital em San Ignacio) e Chiquitos (englobando os cantones San Jose - a capital, Santiago, Santo Corazón, El Cerro, San Juan, Puerto Suárez e San Matias). A análise dos dados desse censo nacional, o primeiro realizado na história da Bolívia, é comprometida pelo fato de que não foram contabilizados os habitantes da região de exploração aurífera (em Santa Rosa de la Mina) e aqueles que viviam nos barracões de exploração dos seringais, ao norte da Chiquitania. Por essa razão, é difícil relacionar estes dados com aqueles de 1825, 1826 e 1830, pois os mesmos não revelam, por exemplo, os movimentos migratórios internos, resultantes da abertura do território Chiquitano à diversificação e intensificação de atividades econômicas.

Durante o primeiro auge da borracha, entre 1880 e 1920, milhares de indígenas foram "alugados" por seus patrões a empresas caucheras ou deportados aos seringais ao norte da Chiquitania, onde tiveram que trabalhar sob o sistema de endividamento encadenado. ${ }^{3}$ Muitos deles morreram em consequência das más condições de trabalho, da desnutrição e da propagação de enfermidades, tais como o paludismo e o beriberi. Não obstante, alguns Chiquitano lograram fugir da deportação e se refugiaram em uma zona de difícil acesso, ao sul da antiga redução de La Concepción, área atualmente chamada de Lomerío, onde fundaram comunidades independentes. Por outro lado, durante este período, a alimentação da população nos seringais requereu um aumento na produção agrícola e pecuária que se levou a cabo em estabelecimentos de produção mista na Chiquitania, com mão de obra indígena.

A demanda crescente por mão de obra originou o comércio de pessoas, chamado reenganche. Tal prática consistia em aliciar indígenas, enganando-os ou comprando as contas aos antigos patrões. Isso tudo acontecia, geralmente, com a anuência das autoridades. $\mathrm{O}$ reenganche consistiu em grave ameaça aos indígenas habitantes das antigas missões e muitos deles, a fim de evitar serem levados a 
Séculos de história indígena no coração da América do Sul...

trabalhar nos seringais, fugiram de seus pueblos de origem. Outros, depois de cumprir contratos com os seringueiros, não mais regressaram ao trabalho e o resultado dessa situação foi uma intensa migração interna, em que os indígenas procuraram proteção junto a fazendeiros, quando não saíram da região, em busca de melhores condições de vida.

Segundo Jürgen Riester, o sistema adotado nos seringais praticamente não permitia aos Chiquitano emanciparam-se dos patrões. Uma das alternativas seria a fuga, mas isso só foi possível em alguns poucos casos, pois enquanto o indígena adulto recolhia látex em meio à mata nativa (em um período aproximado de sete meses ao ano), seus filhos e esposa encontravam-se no assentamento principal, chamado barracón, também trabalhando para o patrão. No caso em que o indígena conseguisse reunir toda a sua família para a fuga, imediatamente se iniciava uma perseguição que, não raro, terminava na morte de todos os membros da família fugitiva, a tiros. Riester coletou inúmeras narrativas de indígenas que estiveram diretamente envolvidos com a extração da borracha ou de seus descendentes (RIESTER, 1976, p. 135-136).

Apesar de conter pouca informação, um relatório escrito no início da década de 1910 oferece pistas importantes para a compreensão da migração de indígenas da Bolívia para o Brasil nesse período. Curt Nimuendaju, no Relatório sobre os Xavante de Mato Grosso, de 1913, registrou a presença de indígenas Chiquitano no antigo sul de Mato Grosso, atual Mato Grosso do Sul.

De acordo com o relatório:

Em 1896 veio a Vacaria Don Ramón Coimbra, boliviano, nascido em Sta. Cruz de La Sierra. Durante dois anos e meio ele exercera lá o cargo de "corregedor" na povoação indígena Sto. Corazón, dos índios Chiquitos sendo que foi prorrogado neste cargo por pedido geral dos índios e dos nacionais. Em sua companhia vieram, com autorização do governo boliviano 14 homens e 4 mulheres da nação dos Chiquitos com o fim de procurar trabalho no Brasil. [...] Dos 18 índios Chiquitos que vieram com D. Ramón da Bolívia só um agüentou ao lado do seu antigo patrão até hoje [1913], 
o resto voltou, morreu ou se espalhou. É um índio já idoso, de nome Manoel Jesus, nascido no Pueblo de San Rafael. É um camarada exemplar, fiel e de toda confiança, que se dá muito com os Ofaié (NIMUENDAJU, 1993, p. 105; 136).

Nesta mesma época, em território boliviano, as condições de trabalho dos indígenas eram as piores possíveis. Os homens nos seringais eram obrigados a trabalhar sem descanso, debaixo de chuva ou sol, inclusive aos domingos e feriados dedicados aos santos. Castigos corporais, torturas e até mesmo assassinatos eram comuns. Os indígenas também eram obrigados a trabalhar por pagamentos irrisórios, sem contar que permaneciam sempre endividados, por conta dos preços exorbitantes praticados pelos patrões em relação à aquisição de roupas, bebidas alcoólicas e tabaco, além de alimentos. Como as dívidas eram cobradas de forma hereditária, famílias inteiras eram obrigadas a se manterem submetidas ao jugo dos patrões por décadas.

O periódico La voz del pueblo, o primeiro a circular pela região da Chiquitania, a partir de 1913, assim se refere a essa situação:

Han habido casos que se han llevado indígenas a las regiones gomeras, allí han fallecido y regresado el patrón al pueblo domiciliario del difunto, presentarle a la viuda la imaginaria cuenta, i por esto quitar violentamente a los hijos de mayor edad; i a falta de la familia despojarle de su miserable cabaña en pago de lo adeudado (LA VOZ DEL PUEBLO, 1º. jun. 1914).

Ainda que o periódico fosse de propriedade de um dos donos de seringais, Exequiel Flores, por meio da cuidadosa leitura de suas páginas é possível perceber certos matizes da exploração desumana a que foram submetidos os Chiquitano e outros indígenas na extração da borracha. Entre 1913 e 1915, foram publicadas dezenas de exemplares em que foram feitas defesas dos indígenas, denúncias de maus tratos, reclamações por uma melhor educação, além de se advogar uma indústria seringueira mais eficiente e produtiva. ${ }^{4}$ Com a morte de Flores, a pequena imprensa foi vendida a religiosos franciscanos, o que significou o fim da publicação de La voz. del pueblo. 
A decadência da produção da borracha (caucho), a consequente derrocada da produção agropecuária e o fim da Guerra do Chaco (1932-1935) entre Bolívia e Paraguai (para a qual os Chiquitano haviam sido recrutados, assim como o restante da população masculina), liberaram milhares de indígenas da servidão e do serviço militar, proporcionando-lhes a oportunidade de formarem comunidades livres. Contudo, um novo auge da borracha, motivado pela Segunda Guerra Mundial, a construção da via férrea entre Bolívia e Brasil (1939-1954) e a recuperação do setor pecuário comercial demandaram uma vez mais mão de obra que foi recrutada entre a população indígena. Riester afirma que os Chiquitano desempenharam importante papel na Guerra do Chaco, embora os méritos desta participação jamais tenham sido reconhecidos pelo Estado boliviano. De acordo com o antropólogo, aos ex-combatentes fora prometida pelo governo uma renda mínima, a fim de lhes assegurar uma velhice tranquila, e até o início dos anos 1970, de fato, “[...] ni um solo chiquitano había recibido renta alguna” (RIESTER, 1976, p. 127).

Ainda que pouco tempo após o término da Guerra do Chaco, em 1937, tenha sido abolido o empadronamiento forzoso, as condições de trabalho para os Chiquitano não mudaram substancialmente: nos seringais e estâncias pecuárias, os indígenas continuaram trabalhando sob o sistema de reenganche. O salário nas fazendas consistia, todavia, na década de 1960, somente em três metros de lienzo (tecido de linho, cânhamo ou algodão) para as mulheres e duas calças e duas camisas para os homens, por ano. Se bem que na construção da via férrea os Chiquitano já haviam trabalhado pela primeira vez recebendo dinheiro, os contratantes retiveram, em geral, entre 30 e $50 \%$ de seus soldos. Durante todo esse tempo, havia muitos Chiquitano que logravam escapar da servidão e refugiaram-se em Lomerío. Na segunda metade dos anos 1940, as empresas internacionais abandonaram definitivamente os seringais e a produção agrícola entrou em crise, já que os produtos agrícolas passaram a ser importados através da via férrea que unia a Bolívia com o Brasil. Este declínio provocou a dispensa de muitas famílias Chiquitano dos estabelecimentos agropecuários, que passaram a formar suas próprias comunidades, concentradas, sobretudo, em torno das antigas reduções e da via férrea. 
Após a Revolução de 1952, os dirigentes do MNR (Movimiento Nacionalista Revolucionario) fixaram um salário mínimo diário de 5. $\$$ b (cinco pesos bolivianos) para os trabalhadores agrícolas de todo o país, incluindo os da Chiquitania, além de responsabilizarem os patrões pelo fornecimento de três refeições diárias aos trabalhadores ou a pagarem 3. - \$b (três pesos bolivianos) suplementares. A maior parte dos proprietários dos estabelecimentos agrícolas rechaçou a medida e o governo, conclamando a população rural, interveio com forças militares. Muitos proprietários de haciendas, que durante anos haviam se beneficiado de uma mão de obra barata, decidiram transformar os estabelecimentos agrícolas em estancias ganaderas, voltadas somente para a pecuária. Com isso reduziram custos, pois a nova atividade não requeria grande mão de obra, implicava menores riscos financeiros e não trazia tantos problemas de transporte e de venda como os produtos agrícolas (RIESTER, 1976, p. 137).

A reforma agrária de 1953 aboliu o latifúndio, distribui terras aos campesinos andinos e, mais tarde, aos indígenas das planícies. Entretanto, a lei da reforma desconsiderou o uso que as populações indígenas das "terras baixas" faziam tradicionalmente dos recursos faunísticos e florísticos. A desintegração de territórios ancestrais comunais em pequenas comunidades, concebidas a partir das atividades agropecuárias, restringiu o acesso dos indígenas ao conjunto de recursos naturais, ainda que seguissem caçando, pescando e coletando fora das terras tituladas. O Estado boliviano reservou para si a propriedade sobre a vegetação e sobre os recursos do subsolo, cujo aproveitamento se fazia mediante concessões outorgadas a empresas privadas ou estatais, o que impedia a exploração comercial pelos próprios grupos nativos.

A má aplicação da lei resultou na superposição de títulos cartoriais e na outorga de concessões de uso em áreas tradicionalmente utilizadas pelos indígenas. Inúmeros conflitos passaram a ocorrer entre indígenas e não indígenas e a presença de grandes propriedades privadas e de intensa atividade madeireira em terras ocupadas outrora por indígenas tiveram uma série de impactos negativos para os Chiquitano. Houve acentuada diminuição dos recursos da fauna, desaparição de madeiras valiosas, além de o acesso a fontes de água tornar-se cada vez mais difícil (PUHL, 2011). Não é à toa, 
Séculos de história indígena no coração da América do Sul...

que nessa época, muitos Chiquitano decidiram abandonar o Oriente boliviano e iniciaram um processo migratório em direção a outros países, notadamente o Brasil.

Finalmente, a última etapa da liberação dos Chiquitano da servidão aconteceu na década de 1960, quando a reforma agrária, proclamada em 1953, alcançou, com certo atraso as "terras baixas". Desde essa época, praticamente o conjunto dos Chiquitano vive em suas próprias comunidades, em cinco províncias do departamento de Santa Cruz, sendo que milhares também vivem nas cidades.

\section{Os chiquitano na segunda metade do século XX (décadas de 1960, 70 e 80)}

Os Chiquitano, apesar de constituírem uma minoria étnica na Bolívia atual, formam há algum tempo a maior população indígena do Oriente boliviano. E ainda que o Espanhol tenha tomado o lugar social da língua Chiquitano, há localidades em que os adultos se comunicam entre si apenas na língua indígena, transmitindo-a, parcialmente, a seus filhos e netos. A base da subsistência da maioria do Chiquitano continua sendo a agricultura, a pesca e a caça. Para ganhar dinheiro trabalham na agricultura e na pecuária regionais, que se encontram em mãos de particulares ou da Igreja Católica. Grande parte da economia local funciona na atualidade, unicamente, pela dependência econômica dos Chiquitano em relação aos não índios. A partir da década de 1980, os indígenas das diferentes áreas da Chiquitania têm formado organizações próprias, cujo principal objetivo é a defesa e consolidação de seus territórios, bem como a realização de projetos de desenvolvimento socioeconômico das comunidades.

$\mathrm{Na}$ Bolívia, os Chiquitano não se autodenominam indígenas nem mesmo são denominados assim pela população não indígena daquele país, pois:

Las comunidades indígenas son llamados ranchos por los chiquitanos, y comunidades campesinas por la sociedad nacional, en un intento luego de 1953, de rechazar la 
connotación peyorativa y racista que aquella época tenía el vocablo "indio" y por extensión "indígena” (TONELLI JUSTINIANO, 2004, p. 334).

Riester estabelece uma tipologia para os diferentes núcleos populacionais onde vivem os Chiquitano na Bolívia: ranchos (aldeias habitadas unicamente por indígenas); estâncias (propriedade não indígena, de criação de gado), geralmente cercadas por ranchos; haciendas (propriedade de mestižos, voltada para a produção agrícola); pueblos (antigas missões jesuíticas, em que predomina população não indígena); ranchos y pueblos (apesar dos mesmos nomes, diferentes dos já citados, por estarem localizados especificamente ao longo da linha férrea que liga Santa Cruz de la Sierra a Corumbá) e barracones (povoados ainda existentes nos seringais de Nuflo de Chávez e Velasco). O antropólogo assinala que existem diferenças entre os habitantes indígenas de cada um desses núcleos, bem como entre províncias, principalmente nas atividades econômicas e, também, nas relações estabelecidas pelos indígenas com a sociedade nacional (RIESTER, 1976, p. 129).

A organização de comunidades indígenas, ou ranchos, na Chiquitania boliviana, tal como se conhece hoje em dia, deu-se a partir da segunda metade do século XX, depois dos períodos de extração da borracha, da Guerra do Chaco e da construção da estrada de ferro entre o Brasil e a Bolívia. Influenciou, também, nesse processo o colapso econômico da agricultura comercial, ocorrido entre o final da década de 1940 e meados da década de 1950, quando os estancieros perderam o interesse pelo cultivo de grandes superfícies, preferindo a criação de gado, ficando a produção agrícola a cargo dos Chiquitano. Isso não significou, contudo, um avanço para os indígenas, posto que os mesmos trocavam os produtos da agricultura e da caça por toda sorte de artigos industrializados, levados até a região por comerciantes que vendiam também bebidas alcoólicas.

Tonelli Justiniano salienta ainda que:

En los años [19]50 y posteriores se presenta un tercer factor, que estimuló e impulsó grandemente el proceso de nuclearización rural: la promulgación de la Ley Reforma Agraria, 
que libera a los indígenas del régimen del empatronamiento forzoso y obliga a los empresarios a pagarles un salario justo. Se estima que durante los años 60, 70 y 80 [do século XX], el número de comunidades indígenas se triplica o cuadruplica (TONELLI JUSTINIANO, 2004, p. 335).

Foi somente a partir da segunda metade da década de 1980 que os Chiquitano foram progressivamente conquistando espaços sociais mais amplos e fazendo valer direitos históricos que, por séculos, lhes foram sistematicamente negados. Esse movimento culminou com o processo de consolidação territorial das populações indígenas, sob o conceito de TCO (Tierras Comunitarias de Origen), iniciado em 1990 com a Marcha por Territorio y la Dignidad e ainda em curso. A crescente denúncia de abusos na outorga de títulos fundiários, as políticas internacionais em favor da conservação do meio ambiente e o fortalecimento do movimento indígena conduziram, nos anos 1990, a uma reformulação das leis agrárias. Este é um processo que apresenta outros desdobramentos, uma vez que a visibilidade dos Chiquitano atualmente é muito maior do que no passado, tendo em vista que um conjunto de antigos templos jesuíticos (San Francisco Javier, Concepción, Santa Ana, San Miguel, San Rafael e San Jose) foi selecionado, em 1990, pela Unesco (Organização das Nações Unidas para a Educação, a Ciência e a Cultura) como Patrimônio da Humanidade.

\section{Considerações finais}

As missões religiosas no Oriente boliviano, assim como na América Portuguesa, "[...] foram instrumentos importantes da política colonial, empreendimentos de expansão territorial e das finanças da Coroa, [...]", constituindo-se em “[...] unidades básicas de ocupação territorial e de produção econômica [...]”, onde houve “[...] uma intenção inicial explícita de promover uma acomodação entre diferentes culturas homogeneizadas pelo processo de catequese e pelo disciplinamento do trabalho" (OLIVEIRA, 2004, p. 25). 
Se as missões constituíram-se em uma espécie de eventochave para se explicar a gênese e a trajetória histórica do que se convencionou chamar até os dias de hoje de Chiquitano, é inegável que eventos ulteriores deram novas e diversificadas formas a essa configuração étnica. Para o século XX, depois do auge da borracha, nenhum outro evento foi tão ou mais significativo para a história dos indígenas quanto à construção da ferrovia Santa Cruz de la Sierra-Corumbá. A partir da década de 1950, novos pueblos y ranchos foram organizados ao longo da extensão da ferrovia, próximos à antiga Missão de San Jose.

Em 1987, o número de indígenas Chiquitano na Bolívia estava entre 35.000 e 40.000, vivendo no interior do Departamento de Santa Cruz, nas províncias Nuflo Chavez, Velasco, Chiquitos e Sandóval, constituindo um dos grupos étnicos mais numerosos do país. Tais números estão de acordo com aquele publicado na obra ZúbakaLa Chiquitania (RIESTER, 1986). No início dos anos 1990, a CPE (Constitución Política del Estado), promulgada na Bolívia, finalmente reconheceu o país como “multiétnico y pluricultural', possibilitando um repensar sobre a forte presença indígena naquele país, em que pesem séculos de exploração e de tentativas de apagamento das diferenças.

\section{DIGENOUS HISTORY IN THE HEART OF SOUTH AMERICA: THE CHIQUITANOS IN THE (ACTUAL) BOLIVIAN EAST}

Abstract: Formerly known also as Trabacicosis or Tapuymiri, Chiquito or Chiquitano, is nowadays, generally, the definition of small indigenous groups, of all varieties, that was met by the Jesuit mission (1691-1767) in the actual Bolivian "low-lands". This action can be summarized in two main aspects: the indigenous agglomeration in reductions or missions and the imposition of a unique language, the Chiquitano, as a general language. About the group's history it is possible to establish a division into phases: from 1542 to 1620 (the indigenous conquest and domination), 1620 to 1962 (the perambulation of many groups around Chiquitania and the eventual hunting by Spanish and Portuguese men in order to slavery), 1692 to 1767 (indigenous Christianization), 1767 until nowadays (events that point out intense contact among Chiquitano and non-indigenous, after reduction's period). Although Jesuitical missions represented an incisive event in Chiquitano's history, they upheld the destruction of traditional political, social, economic, cultural and religious structures, as well as the mixture of several groups, even those which 
were enemies. The past and the present of the Chiquitano are closely related to the Jesuitical mission project, developed between the end of the XVII century and the beginning of the first half of the XVIII. Attempts of living together, imposition of different cultural behaviors, other significations for practices and representations, intercultural dialogues and armed resistance were ingredients found in this history. The objective of this article is, then, to present a synthesis of the ethnohistoric trajectory about the Chiquitano indigenous, between XVI and XX centuries.

Keywords: Indigenous history. Chiquitano. South America. Bolivian East. Jesuitical missions

\section{Notas}

${ }^{1}$ Hernando Sanabria Fernández fornece outra data para esta batalha: 1696 (SANABRIA FERNÁNDEZ, 1995, p. 36).

${ }^{2}$ Depois do período jesuítico, em relação aos Chiquitano, a exploração da borracha é um dos períodos mais estudados pela historiografia boliviana, embora maciçamente de uma perspectiva mais econômica do que social (LEMA GARRET, 2009).

${ }^{3} \mathrm{O}$ endividamento encadenado consistia num sistema em que não apenas o trabalhador, mas toda sua família, desenvolvia-se em dívidas, sendo que essas se transmitiam hereditariamente.

${ }^{4}$ Dos exemplares consultados, destacam-se os de $n^{\circ} .07, n^{\circ} .09, n^{\circ} .10$ (Editorial), e n ${ }^{\circ} .24$ (Editorial).

\section{Referências}

BALZA ALARCÓN, Roberto. Uso contemporáneo del espacio y territorialidad entre los Chiquitanos de Bolivia. In: SILVA, Joana Aparecida Fernandes (Org.). Estudos sobre os Chiquitanos no Brasil e na Bolivia: história, língua, cultura e territorialidade. Goiânia: UCG, 2008. p. 265-288.

D'ORBIGNY, Alcide Dessalines. Fragment d'un voyage au centre de l'Amérique Meridionale. Paris/Strasbourg: Bertrand/Levrault, 1845. 584p.

FERNÁNDEZ, Juan Patricio. Relacion historial de las Misiones de indios chiquitos que en el Paraguay tienen los padres de la Compañia de Jesús. Madrid: Victoriano Suárez, 1895. 282p. (Tomo I). (Colección de libros raros ó curiosos que tratan de America). 
. Relacion historial de las Misiones de indios chiquitos que en el Paraguay tienen los padres de la Compañia de Jesús. Asunción: A. de Uribe y Compañia, 1896. 325p. (Tomo II).

FINOT, Enrique. Historia de la conquista del oriente boliviano. La Paz: Juventud, 1978. 388p.

GRONDONA, José Esteban. Descripción sinóptica de la provincia de Chiquitos. Revista Universitaria de San Francisco Javier, Sucre, v. 11, n. 27/28, 1942.

JOSÉ DA SILVA, Giovani. A presença Camba-Chiquitano na fronteira Brasil Bolivia (1938-1987): identidades, migrações e práticas culturais. 2009. 292 f. Tese (Doutorado em História) - UFG, Universidade Federal de Goiás, Goiânia. 2009.

KLEIN, Herbert S. Bolivia: do período pré-incaico à independência. Tradução de Alberto Alexandre Martins; Maria da Glória P. Kok. São Paulo: Brasiliense, 1991. 80p. (Tudo é História, 137).

KREKELER, Birgit. Historia de los Chiquitanos. Tradução de Peter Dressendörfer. Santa Cruz de la Sierra: APCOB, 1995. 239p. (Pueblos indígenas de las tierras bajas de Bolívia, 2).

LA VOZ DEL PUEBLO, "Por los indigenas" (Editorial), Santa Ana de Velasco, Bolivia, n. 24, 1º de junio de 1914.

LEMA GARRET, Ana María. El sentido del silencio: la mano de obra chiquitana en el Oriente boliviano a principios del siglo XX. La Paz: El País, 2009. 221p. (Colección Ciencias Sociales, 14).

LOBO, Maria Eulália Lahmeyer. Caminho de Chiquitos às missões Guaranis de 1690 a 1718. Revista de História, São Paulo, USP, n. 40, p. 05-84, 1960.

MÉTRAUX, Alfred. The Native Tribes of Eastern Bolivia and Western Matto Grosso. Bulletin of the BAE (Bureau of American Ethnology), Washington (D.C.), n. 134, p. 114-134, 1942.

MOLINA MOSTAJO, Plácido. Historia del Obispado de Santa Cruz de la Sierra: capítulos relacionados con la cuestión del Chaco Boreal. La Paz: [s.e.], 1936. 182p.

NIMUENDAJU, Curt. Etnografia e indigenismo: sobre os Kaingang, os OfaiéXavante e os Índios do Pará. GONÇALVES, Marco Antonio (Org. e Apres.). Campinas: Unicamp, 1993. 160p.

OLIVEIRA, João Pacheco de. Uma etnologia dos “índios misturados”? Situação colonial, territorialização e fluxos culturais. In: . (Org.). A viagem da volta: etnicidade, política e reelaboração cultural no Nordeste indígena. 2. ed. Rio de Janeiro: Contracapa/Laced, 2004. p. 13-42. (Territórios Sociais). 
Séculos de história indígena no coração da América do Sul...

PUHL, João Ivo. Territorialidades chiquitanas em comunidades rurais da Provincia de Velasco - Bolivia - 1953-2006. 2011.285f. Tese (Doutorado em História) - Unisinos, Universidade do Vale do Rio dos Sinos, São Leopoldo. 2011.

RIESTER, Jürgen. En busca de la loma santa. La Paz/Cochabamba: Los Amigos del Libro, 1976. 376p. . Julian Knogler S. J. und die Reduktionen der Chiquitano in Ostbolivien. Via Dei Penitenzieri, Roma, n. 39, p. 268-349, 1970. . Zúbaka La Chiquitanía: visión antropológica de una región en desarrollo. Cochabamba/La Paz: Los Amigos del Libro, 1986. 387p. (Tomo I - Vocabulario del Chiquito).

SANABRIA FERNÁNDEZ, Hernando. Breve Historia de Santa Cruz. 3. ed. La Paz: Juventud, 1995. 162p.

TOMICHÁ CHARUPÁ, Roberto. La formación socio-cultural de los Chiquitanos en el Oriente Boliviano (Siglos XVI-XVIII). In: SILVA, J. A. F. (Org.). Estudos sobre os Chiquitanos no Brasil e na Bolívia: história, língua, cultura e territorialidade. Goiânia: UCG, 2008. p. 223-264.

. La Iglesia en Santa Cru₹: 400 años de historia (1605-2005). Cochabamba:

Verbo Divino, 2005. 100p.

TONELLI JUSTINIANO, Oscar. Reseña histórica, socialy económica de la Chiquitania. Santa Cruz de la Sierra: El País, 2004. 405p.

WACHTEL, Nathan. Os índios e a conquista espanhola. In: BETHELL, Leslie. (Org.). História da América Latina: América Latina colonial. Tradução de Maria Clara Cescato. 2. ed. São Paulo/Brasília: Edusp/Fundação Alexandre de Gusmão, 2004. p. 195-239.

Recebido em: 27/10/2011

Aprovado em: 15/12/2011 